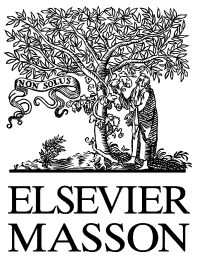

Available online at Elsevier Masson France

ScienceDirect

www.sciencedirect.com

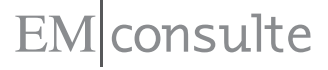

www.em-consulte.com
Revue d'Épidémiologie et de Santé Publique

Revue d'Épidémiologie et de Santé Publique xxx (2015) xxx-xxx

\title{
Distribution and etiology of chronic respiratory diseases in primary healthcare departments in Cape Verde
}

\author{
Distribution et étiologie des maladies respiratoires chroniques au Cap-Vert dans des \\ structures de soins de santé primaires \\ P. Carreiro-Martins ${ }^{\mathrm{a}, \mathrm{b}, *}$, J. Rosado-Pinto $^{\mathrm{c}}$, M. do Céu Teixeira ${ }^{\mathrm{d}}$, N. Neuparth ${ }^{\mathrm{a}, \mathrm{b}}$, \\ O. Silva ${ }^{\mathrm{e}}$, A.L. Papoila ${ }^{\mathrm{f}}$, N. Khaltaev ${ }^{\mathrm{g}}$, J. Bousquet ${ }^{\mathrm{h}, \mathrm{i}}$, I. Annesi-Maesano ${ }^{\mathrm{j}, \mathrm{k}}$ \\ ${ }^{a}$ Serviço de Imunoalergologia, Hospital de Dona Estefânia, Centro Hospitalar de Lisboa Central, EPE, Lisbon, Portugal \\ ${ }^{\mathrm{b}}$ CEDOC, Chronic Diseases Research Centre - Respiratory Group, NOVA Medical School / Faculdade de Ciências Médicas, \\ Universidade NOVA de Lisboa, Campo dos Mártires da Pátria, 130, 1169-056 Lisbon, Portugal \\ ${ }^{\mathrm{c}}$ Hospital da Luz, Lisboa, Portugal \\ ${ }^{\mathrm{d}}$ Agostinho Neto Hospital, Praia, Cabo Verde \\ ${ }^{\mathrm{e}}$ Dr. Baptista de Sousa Hospital, Mindelo, Cabo Verde \\ ${ }^{\mathrm{f}}$ Departamento de Bioestatística e Informática, CEAUL, Faculdade de Ciências Médicas (FCM), Universidade Nova de Lisboa, Lisbon, Portugal \\ ${ }^{\mathrm{g}}$ WHO/GARD Secretariat, Geneva, Switzerland \\ ${ }^{\mathrm{h}}$ Department of Respiratory Diseases, hôpital Arnaud-de-Villeneuve, University Hospital, Montpellier, France \\ ${ }^{\mathrm{i}}$ Inserm, CESP Centre for research in Epidemiology and Population Health, U1018, Respiratory and Environmental Epidemiology Team, Villejuif, France \\ ${ }^{\mathrm{j}}$ Inserm, UMR-S 1136, i-PLESP : EPAR, 75012 Paris, France \\ ${ }^{\mathrm{k}}$ Université Pierre et Marie Curie, Paris 6, UMR-S 1136, i-PLESP : EPAR, 75012 Paris, France
}

Received 11 August 2014; accepted 3 June 2015

\begin{abstract}
Background and objective. - Data on chronic respiratory diseases (CRD) are scarce or unavailable in most African countries. We aimed to determine the prevalence of CRD and associated risk factors in Cape Verde, at the primary healthcare level.

Methods. - In the frame of the Global Alliance Against Chronic Respiratory Diseases, a cross-sectional study was carried out in October 2006 in 3256 outpatients ( 2142 women) (median age of 30 years) seeking care at primary healthcare departments, through a standardized interview questionnaire during two weeks.

Results. - The prevalence of emphysema, tuberculosis, chronic bronchitis, rhinoconjunctivitis and asthma were $0.7 \%, 2 \%, 4.5 \%, 12.3 \%$ and 6.2\%, respectively. Current smoking was associated with emphysema (OR: 3.36; 95\% CI: 0.97-11.40) and tuberculosis (OR: 2.14; 95\% CI: 1.074.30), ever exposed to a dusty workplace with chronic bronchitis (OR: 2.20; CI 95\%: 1.50-3.21) and rhinoconjunctivitis (OR: 1.56; CI 95\%: 1.231.98 ) and cooking or heating using an open fire with asthma (OR: 1.59; CI 95\%: 1.16-2.19). The estimates of attributable risks percent indicated that, in the sample, a noticeable part of CRD could be attributed to active smoking, exposure to dust and biomass. Results varied according to gender, particularly regarding current smoking which was more important for men.

Conclusions. - Tobacco smoking, exposure to dust at work and using an open fire were important risk factors for CRD. Our results suggest that if actions were taken in order to reduce the aforementioned exposures, an important CRD decrease could be achieved.

(C) 2015 Elsevier Masson SAS. All rights reserved.
\end{abstract}

Keywords: Asthma; COPD; Tuberculosis; Rhinitis; Attributable risk; Smoking; Dust; Biomass

\section{Résumé}

Position du problème. - Peu de données épidémiologiques sont disponibles sur les maladies respiratoires chroniques (MRC) dans la plupart des pays africains. Nous avons déterminé, au niveau des structures de soins de santé primaires, la prévalence des MRC et les facteurs de risque leur étant associés dans la République du Cap-Vert.

\footnotetext{
* Corresponding author.

E-mail address: pmartinsalergo@gmail.com (P. Carreiro-Martins).
} 
Méthodes. - Dans le cadre de la Global Alliance Against Chronic Respiratory Diseases (GARD), une étude transversale a été réalisée pendant 2 semaines en octobre 2006 parmi les patients accueillis dans des structures de soins de santé primaires. Les sujets ont répondu à un questionnaire standardisé administré par des personnels de santé.

Résultats. - Au total, 3256 patients (2142 femmes) (âge médian de 30 ans) ont participé à l'enquête. La prévalence de l'emphysème, de la tuberculose, de la bronchite chronique, de la rhino-conjonctivite et de l'asthme était de $0,7 \%, 2 \%, 4,5 \%, 12,3 \%$ et $6,2 \%$, respectivement. Le tabagisme à la période de l'enquête était significativement associé à l'emphysème (OR : 3,36, IC 95 \%: 0,97-11,40) et à la tuberculose (OR : 2,14, IC $95 \%$ : 01,07-04,30), l'exposition professionnelle aux poussières à la bronchite chronique (OR : 2,20; IC 95\%:1,50-3,21) et à la rhinoconjonctivite (OR : 1,56, IC $95 \%: 1,23-1,98)$, et la cuisson ou le chauffage utilisant un foyer ouvert était associé à l'asthme (OR : 1,59, IC 95\% : 1,16-2,19). Les estimations des risques attribuables (\%) ont indiqué que, dans l'échantillon, une partie non négligeable des MRCs pourrait être attribuée au tabagisme actif, à l'exposition à la poussière et à la biomasse. Les résultats variaient selon le sexe, en particulier pour le tabagisme actuel, plus important pour les hommes.

Conclusion. - Le tabagisme, l'exposition professionnelle aux poussières et l'utilisation d'un chauffage utilisant un foyer ouvert sont des facteurs de risque importants des CRD. Nos résultats suggèrent que des mesures de réduction de ces risques conduiraient à une diminution des MRC. (C) 2015 Elsevier Masson SAS. Tous droits réservés.

Mots clés : Asthme ; Biomasse ; BPCO ; Poussière ; Rhinite ; Risque attribuable ; Tabac ; Tuberculose

\section{Introduction}

Chronic obstructive pulmonary disease (COPD) affects more than 210 million people worldwide [1], and asthma as many as 300 million. More than 400 million people suffer from allergic rhinitis [2]. However, these diseases are often underdiagnosed and undertreated, resulting in underestimation of their burden [3,4]. Data on chronic respiratory diseases (CRD) are scarce or unavailable in most African countries.

Tobacco smoking is the single most important factor in the genesis of COPD [5,6] and it seems to have also an association with tuberculosis [7]. Besides tobacco, other environmental risk factors are also well known for COPD, e.g. occupational exposure. A number of studies in Africa have shown that COPD is associated with workplace pollution and indoor air pollution from biomass fuel, which appears to contribute to COPD in women in developing countries [8]. Asthma and allergic rhinitis risk factors in Sub-Saharan Africa are even less known [9,10], especially for adults.

The aim of our epidemiological survey on CRD and related risk factors was to assess the burden of CRD at the primary healthcare level in Cape Verde. The secondary purpose was to identify differences in CRD distribution and etiology between men and women. The survey also provided specific training for professionals, facilitating the development of prevention and treatment programs.

\section{Methods}

This study resulted from an official protocol between the Ministry of Health from Portugal and Cape Verde and was included in the Global Alliance Against Chronic Respiratory Diseases (GARD) initiative [11], in accordance with the previously published protocol [12].

\subsection{Study design}

This was a cross-sectional study carried out in Cape Verde, in order to assess the prevalence of CRD (defined on the basis of reported asthma, chronic bronchitis, emphysema, tuberculosis and allergic rhinitis) at the primary healthcare level, by estimating their point prevalence and to identify risk factors associated with them. Spirometric results from a small sample were published elsewhere [12].

The study and analyses reporting were conducted according to the STROBE (Strengthening the reporting of observational studies in epidemiology) initiative [13].

\subsection{Setting}

The study took place at Primary Healthcare (PHC) and Emergency Room Departments (ER) in Santiago and São Vicente islands (Cape Verde), in October 2006 during two weeks. All the PHC and ER Departments in Santiago and São Vicente islands were included in the survey.

\subsection{Participants}

The target population was constituted by outpatients older than six year's old seeking care at PHC and ER Departments in Santiago and São Vicente islands. Participants were selected using a consecutive sampling scheme, logistically the easiest methodology to implement. In this sense, all the outpatients attending all the PHC in Cape Verde were invited to participate in the survey by filling in a standardized questionnaire. In 2010, the population had a median age of 22 years and $50.5 \%$ were women.

\subsection{Data source}

Data were collected using a questionnaire administered by staff personnel trained and certified by the Cape Verde GARD team. The questionnaire included standardized questions about respiratory symptoms and diseases and risk factors (smoking history, type of cooking...) from the burden of obstructive lung disease (BOLD) initiative [14].

According to the standardized definition, chronic bronchitis was defined as the presence of cough and sputum production for 
at least three months in each of two consecutive years. Asthma, emphysema, tuberculosis and allergic rhinitis were defined on the basis of the presence of a previous medical diagnosis. Allergic rhinoconjuntivitis (symptomatic criteria) was defined as the presence in the past 12 months of sneezing or runny nose or blocked nose apart from cold or flu and accompanied by itchy-watery eyes. Smoking was assessed as more than 20 packs of cigarettes or $12 \mathrm{oz}$ of tobacco in a lifetime or at least one cigarette a day for one year. A subject who smoked during the last 30 days was considered a current smoker. Occupational exposure was assumed for those who had ever worked for a year or more in any dusty job (or studied in a dusty environment, in the case of children). Open fire exposure was given by an affirmative answer to the question concerning cooking or heating using an open fire.

After informed consent, the questionnaire was administered by an interviewer (doctor or nurse) prior to the medical visit and collected by the general practitioner at the end of the consultation. The interviewer read clearly all the questions and repeated them if the subject did not understand. When after a brief explanation a doubt remained, the answer was considered negative.

\subsection{Variables}

The outcome variables were the presence of allergic rhinitis, allergic rhinoconjuntivitis, asthma, chronic bronchitis, emphysema, and tuberculosis. Smoking, exposure to dust at workplace, and cooking or heating using an open fire were the considered exposures. Gender and age were the considered potential confounders.

\subsection{Statistical analysis}

An exploratory analysis of the variables of interest (gender, age, smoking status, occupational exposure, domestic fuel exposure, chronic bronchitis and reported diseases) was carried out. The point prevalence of asthma, chronic bronchitis, emphysema, tuberculosis and allergic rhinitis were estimated in the sample as the ratio (at the period of the survey) of the number of occurrences of a disease or event to the number of units at risk in the population. The $\mathrm{Chi}^{2}$ test was used to compare proportions.

Logistic regression models were used to explore potential risk factors for the considered diseases: age, gender, smoking status, having been exposed to dust at workplace and cooking or heating using an open fire. Crude regression coefficients and corresponding odds ratio were calculated first. Adjusted odds ratios were determined by fitting a multivariable logistic regression model to the data.

Concerning the multivariable analysis, age and gender were included a priori in all the models, irrespective of their statistical significance. For other covariates, selection began by a univariate analysis. Any variable with a $P$-value lower than 0.20 was selected as a candidate for the multivariable analysis. A purposeful selection was carried out to construct the multivariable model. In the variable selection, covariates were removed from the model if they were non-significant. For more details on the selection process refer to Hosmer and Lemeshow [15].

To overcome a potential effect modification, a stratified analysis by gender was also performed in order to quantify the influence of the exposures on CRD for men and women, separately. Thus, three analyses were done using the same methodology: for the overall sample, and for men and women. Crude and adjusted odds ratios (OR) were calculated with 95\% confidence intervals (CI 95\%).

Attributable risks percent and corresponding 95\% confidence intervals were calculated for exposed groups after adjustment by multivariable logistic regression, using "punaf" STATA command. "Punaf" uses the method for estimating PAFs recommended by Greenland and Drescher for cohort and cross-sectional studies [16].

A sensitivity analysis was also performed after removing the participants reporting more than one CRD.

Missing data were addressed by complete case analysis for the outcome, exposure and confounder variables. The level of significance considered was $\alpha=0.05$, although $P$-values greater than 0.05 and lower than 0.1 were also reported [17]. Data analysis was performed using STATA (StataCorp LP, Stata Statistical Software: Release 12; TX, USA).

\section{Results}

A total of 3256 (81.3\% of the initial population) individuals for whom all the variables of interest were available were included in the analysis. Individuals excluded from the analysis did not differ from the others in asthma diagnosis $(P=0.188)$. However, they presented a significantly lower prevalence of chronic bronchitis $(P=0.032)$, tuberculosis $(P=0.001)$, emphysema $(P<0.001)$ and allergic rhinitis $(P<0.001)$. The description of the sample is presented in Table 1 . The majority of the surveyed sample was constituted by women $(65.8 \%)$ and the median age was 30 years.

Men presented a higher prevalence of chronic bronchitis $(P=0.021)$ and tuberculosis $(P<0.001)$ than women. Smoking $(P<0.001)$ and past exposure to dust at workplace $(P<0.001)$ were also more common in men. Conversely, cooking using an open fire was noted for a higher proportion of women $(P<0.001)$.

Asthma (6.2\%) was the most common disease of the lower airways or lungs, followed by chronic bronchitis (4.5\%), current tuberculosis (2\%) and diagnosis of emphysema (0.7\%). A relevant proportion reported a past exposure to dust at workplace (33.9\%) and to cooking or to heating using an open fire $(40.5 \%)$.

For the overall sample, risk factors identified with the univariable analysis were (OR; CI 95\%): male gender for chronic bronchitis $(1.48 ; 1.06-2.06)$ and tuberculosis (4.05; 2.42-6.77); elderly age for asthma (1.99; 1.23-3.23), chronic bronchitis $(4.66 ; 2.45-8.57)$, and tuberculosis $(9.03 ; 1.94$ 41.98); smoking status (particularly current smoker) for chronic bronchitis $(2.72 ; 1.59-4.65)$, emphysema $(4.90 ; 1.60-15.06)$, and tuberculosis $(4.05 ; 2.42-6.77)$; past exposure to dust for 
Table 1

Description of the population sample stratified by sex.

\begin{tabular}{|c|c|c|c|c|}
\hline & Total & Male & Female & $P$-value \\
\hline Total answers $(n)$ & 3276 & 1120 & 2156 & \\
\hline \multicolumn{5}{|l|}{ Sociodemographic and risk factors } \\
\hline \multicolumn{5}{|l|}{ Age in years } \\
\hline Total-median $(\mathrm{P} 25-\mathrm{P} 75)^{\mathrm{a}}$ & $30.0(20-47)$ & $30.0(18.3-47.0)$ & $30.0(21.0-46.0)$ & 0.054 \\
\hline \multicolumn{5}{|l|}{ Age classes, $n(\%)$} \\
\hline$\leq 19$ yrs & $740(22.6)$ & $312(27.9)$ & $428(19.9)$ & \\
\hline $20-44$ yrs & $1676(51.2)$ & $508(45.3)$ & $1168(54.2)$ & \\
\hline $45-64$ yrs & $484(14.8)$ & $141(12.6)$ & $343(15.9)$ & \\
\hline$\geq 65$ yrs & $376(11.5)$ & $159(14.2)$ & $207(10.0)$ & \\
\hline Smoking status, $n(\%)$ & & & & $<0.001$ \\
\hline Never smoker & $2863(88.9)$ & $849(77.5)$ & $2014(94.8)$ & \\
\hline Former smoker $^{\mathrm{b}}$ & $189(5.9)$ & $127(11.6)$ & $62(2.9)$ & \\
\hline Current smoker & $169(5.2)$ & $120(10.9)$ & $49(2.3)$ & \\
\hline Smoking exposure (current smokers) -pack-years, $n(\%)$ & & & & 0.225 \\
\hline $0.1-9.9$ & $84(49.7)$ & $63(52.5)$ & $21(42.9)$ & \\
\hline $10.0-19.9$ & $37(21.9)$ & $29(24.2)$ & $8(16.3)$ & \\
\hline$\geq 20.0$ & $30(17.8)$ & $27(22.5)$ & $3(6.1)$ & \\
\hline Missing information & $18(10.7)$ & $1(0.8)$ & $17(34.7)$ & \\
\hline Exposure to dust at workplace (1 year or more), $n(\%)$ & $1098(33.9)$ & $431(38.5)$ & $667(30.9)$ & $<0.001$ \\
\hline \multicolumn{5}{|l|}{ Cooking/heating, $n(\%)$} \\
\hline Using an open fire & $1328(40.5)$ & $302(30.0)$ & $1026(47.6)$ & $<0.001$ \\
\hline Coal or coke & $327(9.9)$ & $64(5.7)$ & $263(12.2)$ & \\
\hline Wood & $855(26.1)$ & $173(15.5)$ & $682(31.6)$ & \\
\hline Animal dung & $87(2.7)$ & $18(1.6)$ & $69(3.2)$ & \\
\hline \multicolumn{5}{|l|}{ Respiratory health } \\
\hline \multicolumn{5}{|l|}{ Rhinitis, $n(\%)$} \\
\hline Allergic rhinitis (doctor diagnosis) & $128(3.9)$ & $39(3.5)$ & $89(4.2)$ & 0.249 \\
\hline Allergic rhinoconjuntivitis (symptoms) & $404(12.3)$ & $108(9.6)$ & $296(13.7)$ & 0.314 \\
\hline Asthma*, $n(\%)$ & $203(6.2)$ & $63(5.6)$ & $140(6.5)$ & 0.021 \\
\hline Chronic bronchitis, $n(\%)$ & $149(4.5)$ & $64(5.7)$ & $85(3.9)$ & 0.105 \\
\hline Emphysema*, $n(\%)$ & $24(0.7)$ & $12(1.1)$ & $12(0.6)$ & \\
\hline Tuberculosis*, $n(\%)$ & & & & $<0.001$ \\
\hline Ever & $67(2.0)$ & $45(4.0)$ & $22(1.0)$ & \\
\hline
\end{tabular}

P: percentile, \%: percentage; *: doctor's diagnosis; yrs: years.

${ }^{a}$ Minimum 6 and maximum 97 years.

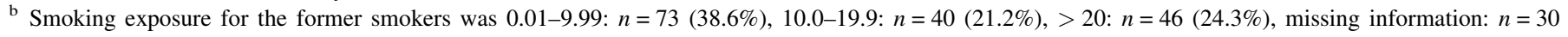
$(15.9 \%)$.

rhinoconjunctivitis $(1.53 ; 1.24-1.90)$, asthma $(1.31 ; 0.98-$ 1.75), chronic bronchitis $(2.47 ; 1.77-3.44)$, emphysema (2.32; 1.03-5.19), and tuberculosis (1.86; 1.14-3.03); and cooking or heating using an open fire for rhinoconjunctivitis $(1.32$; $1.06-$ 1.65), asthma (1.57; 1.15-2.12), and chronic bronchitis (1.75; 1.22-2.50). Protective factors identified were: male gender for rhinoconjunctivitis $(0.25 ; 0.15-0.41)$ and cooking or heating using an open fire, inversely related to allergic rhinitis $(0.48$; 0.32-0.72).

Results persisted for all the diseases after adjustment for potential confounders although the odds ratios were slightly smaller and the statistical significance decreased (Table 2). In particular, rhinoconjunctivitis and asthma were no longer significantly related to cooking or heating using an open fire and dust at workplace, respectively.

Stratification by gender showed that working in a dusty workplace was associated with rhinoconjunctivitis in men and with rhinoconjunctivitis, asthma, chronic bronchitis and tuberculosis in women (Table 3). Cooking or heating using an open fire was associated with increasing risk of asthma, chronic bronchitis and tuberculosis in men and with asthma in women. Allergic rhinitis and cooking or heating with an open fire were inversely related in women.

Attributable risks percent computation (Table 4) for the overall sample showed that an important proportion of emphysema and tuberculosis cases could be attributed to current smoking. A relevant number of the cases of chronic bronchitis and rhinoconjunctivitis could be attributed to dust exposure at the workplace. Concerning cooking or heating using an open fire exposure, it was particularly significant for asthma and chronic bronchitis. In men, an important proportion of chronic bronchitis and emphysema were attributed to smoking. Cooking or heating using an open fire was also a relevant exposure for chronic bronchitis. In men, dust exposure at workplace was significant only for rhinoconjunctivitis. In women, an important part of chronic bronchitis and tuberculosis was attributed to dust exposure at the workplace. Using an open fire was only significant for asthma.

In the sensitivity analysis, after excluding the participants with mixed forms of CRD, the associations between exposures and outcomes persisted with similar ORs, but were less statistically significant or non-significant. 
Table 2

Relationships between chronic respiratory diseases and risk factors-overall sample (multivariable analysis-OR, CI 95\%, $P$-value).

\begin{tabular}{|c|c|c|c|c|c|c|c|c|c|c|c|c|}
\hline \multirow[b]{2}{*}{ Variable } & \multicolumn{2}{|l|}{ Allergic rhinitis $^{1}$} & \multicolumn{2}{|c|}{ Rhinoconjuntivitis $^{2}$} & \multicolumn{2}{|l|}{ Asthma $^{3}$} & \multicolumn{2}{|l|}{ Chronic bronchitis ${ }^{4}$} & \multicolumn{2}{|l|}{ Emphysema $^{5}$} & \multicolumn{2}{|l|}{ Tuberculosis $^{6}$} \\
\hline & OR $(95 \% \mathrm{CI})$ & $P$-value & OR $(95 \% \mathrm{CI})$ & $P$-value & OR $(95 \% \mathrm{CI})$ & $P$-value & OR $(95 \% \mathrm{CI})$ & $P$-value & OR $(95 \% \mathrm{CI})$ & $P$-value & OR $(95 \% \mathrm{CI})$ & $P$-value \\
\hline \multicolumn{13}{|l|}{ Sex } \\
\hline Women & 1 & & 1 & & 1 & & 1 & & 1 & & 1 & \\
\hline Men & $0.60(0.39-0.91)$ & 0.018 & $0.70(0.54-0.91)$ & 0.007 & $1.08(0.77-1.51)$ & 0.670 & $1.68(1.12-2.53)$ & 0.013 & $1.20(0.49-2.93)$ & 0.683 & $3.81(2.18-6.64)$ & $<0.001$ \\
\hline \multicolumn{13}{|l|}{ Age } \\
\hline $6-19 \mathrm{yrs}$ & 1 & & 1 & & 1 & & 1 & & 1 & & 1 & \\
\hline $20-44 \mathrm{yrs}$ & $1.46(0.85-2.50)$ & 0.170 & $1.31(0.90-1.66)$ & 0.192 & $0.99(0.65-1.52)$ & 0.972 & $2.63(1.28-5.42)$ & 0.009 & $1.15(0.23-5.81)$ & 0.864 & $8.81(2.08-37.39)$ & 0.003 \\
\hline $45-64 \mathrm{yrs}$ & $1.15(0.57-2.33)$ & 0.697 & $1.08(0.72-1.60)$ & 0.717 & $1.51(0.90-2.52)$ & 0.121 & $3.00(1.33-6.78)$ & 0.008 & $1.85(0.31-11.08)$ & 0.502 & $13.04(2.87-59.26)$ & 0.001 \\
\hline$>65 \mathrm{yrs}$ & $1.22(0.59-2.53)$ & 0.59 & $0.84(0.54-1.32)$ & 0.452 & $1.97(1.18-3.29)$ & 0.010 & $4.49(2.00-10.10)$ & $<0.001$ & $6.08(1.19-31.04)$ & 0.030 & $7.41(1.52-36.15)$ & 0.013 \\
\hline \multicolumn{13}{|c|}{ Smoking status } \\
\hline Never & $*$ & & $*$ & & $*$ & & 1 & & 1 & & 1 & \\
\hline Former & $*$ & $*$ & $*$ & $*$ & $*$ & $*$ & $1.27(0.66-2.42)$ & 0.476 & $2.84(0.93-8.66)$ & 0.067 & $1.40(0.63-3.12)$ & 0.405 \\
\hline Current & $*$ & $*$ & $*$ & * & $*$ & * & $1.66(0.90-3.10)$ & 0.107 & $3.36(0.97-11.40)$ & 0.051 & $2.14(1.07-4.30)$ & 0.032 \\
\hline
\end{tabular}

Dust at

workplace

Never

Ever

1

1

1

Cooking/heating

Using an

open fire

$\begin{array}{llllllll}\text { No } & 1 & & 1 & 1 & 1 \\ \text { Yes } & 0.41(0.27-0.62) & <0.001 & 1.17(0.93-1.48) & 0.182 & 1.59(1.16-2.19) & 0.004 & 1.98(1.35-2.92)\end{array}$

$1.53(1.02-2.30) \quad 0.040$

$1.56(1.23-1.98)$

10.0001

1

$0.001 \quad *$

The following factors were included in the model: ${ }^{1}$ : sex, age, dust at workplace and cooking/heating using an open fire; ${ }^{2}$ : sex, age, dust at workplace and cooking/heating using an open fire; ${ }^{3}$ : sex, age, dust at workplace

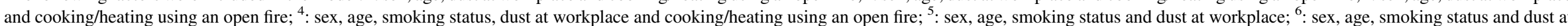
workplace; OR: odds ratio; CI 95\%: 95\% confidence interval; yrs: years; *: corresponding factor not selected for multivariable analysis (univariate $P$-value $>0.20$ ). 
Relationships between chronic respiratory diseases and risk factors for men and women.

\begin{tabular}{|c|c|c|c|c|c|c|c|c|c|c|c|c|}
\hline \multirow[t]{2}{*}{ Variable } & \multicolumn{2}{|l|}{ Allergic rhinitis ${ }^{1}$} & \multicolumn{2}{|l|}{ Rhinoconjuntivitis $^{2}$} & \multicolumn{2}{|l|}{ Asthma $^{3}$} & \multicolumn{2}{|l|}{ Chronic bronchitis $^{4}$} & \multicolumn{2}{|l|}{ Emphysema $^{5}$} & \multicolumn{2}{|l|}{ Tuberculosis $^{6}$} \\
\hline & OR $(95 \% \mathrm{CI})$ & $P$-value & OR (95\% CI) & $P$-value & OR $(95 \%$ CI $)$ & $P$-value & OR $(95 \%$ CI $)$ & $P$-value & OR $(95 \%$ CI $)$ & $P$-value & OR $(95 \% \mathrm{CI})$ & $P$-value \\
\hline \multicolumn{13}{|l|}{ Men } \\
\hline \multicolumn{13}{|l|}{ Age } \\
\hline $6-19 \mathrm{yrs}$ & 1 & & 1 & & 1 & & 1 & & 1 & & 1 & \\
\hline $20-44$ yrs & $0.82(0.36-1.89)$ & 0.644 & $0.76(0.36-1.58)$ & 0.457 & $0.64(0.33-1.24)$ & 0.187 & $2.44(0.88-6.73)$ & 0.085 & $1.03(0.09-11.26)$ & 0.980 & $12.54(1.66-94.75)$ & 0.014 \\
\hline $45-64$ yrs & $0.56(0.16-1.96)$ & 0.367 & $0.72(0.21-2.42)$ & 0.595 & $1.35(0.60-3.02)$ & 0.465 & $3.22(0.98-10.52)$ & 0.053 & $1.08(0.07-16.33)$ & 0.953 & $27.31(3.38-220.72)$ & 0.002 \\
\hline$\geq 65 \mathrm{yrs}$ & $0.37(0.09-1.42)$ & 0.145 & $1.44(0.41-5.02)$ & 0.565 & $1.74(0.84-3.62)$ & 0.139 & $3.74(1.16-12.12)$ & 0.028 & $2.62(0.21-32.14)$ & 0.453 & $8.04(0.85-75.80)$ & 0.068 \\
\hline \multicolumn{13}{|c|}{ Smoking status } \\
\hline Never & * & & $*$ & & * & & 1 & & 1 & & 1 & \\
\hline Former & * & $*$ & * & * & * & $*$ & $1.94(0.90-4.16)$ & 0.091 & $7.92(1.43-43.82)$ & 0.018 & $1.10(0.41-2.93)$ & 0.853 \\
\hline Current & $*$ & $*$ & $*$ & $*$ & $*$ & $*$ & $2.13(1.03-4.38)$ & 0.041 & $8.80(1.67-46.25)$ & 0.010 & $1.95(0.88-4.30)$ & 0.853 \\
\hline \multicolumn{13}{|l|}{$\begin{array}{l}\text { Dust at } \\
\text { workplace }\end{array}$} \\
\hline Never & 1 & & 1 & & * & & 1 & & $*$ & & $*$ & \\
\hline \multicolumn{13}{|l|}{ or more } \\
\hline \multicolumn{13}{|c|}{ Cooking/heating } \\
\hline \multicolumn{13}{|l|}{$\begin{array}{l}\text { Using an } \\
\text { open fire }\end{array}$} \\
\hline No & * & & $*$ & & 1 & & 1 & & * & & 1 & \\
\hline Yes & * & * & * & $*$ & $1.70(0.99-2.91)$ & 0.055 & $2.93(1.68-5.12)$ & $<0.001$ & * & * & $1.86(0.96-3.62)$ & 0.068 \\
\hline \multicolumn{13}{|l|}{ Women } \\
\hline \multicolumn{13}{|l|}{ Age } \\
\hline $6-19$ yrs & 1 & & 1 & & 1 & & 1 & & 1 & & $\dagger$ & \\
\hline $20-44$ yrs & $2.60(1.15-5.88)$ & 0.021 & $0.82(0.47-1.47)$ & 0.474 & $1.35(0.75-2.44)$ & 0.315 & $2.27(0.88-5.89)$ & 0.091 & $0.98(0.10-9.65)$ & 0.988 & $\dagger$ & $\dagger$ \\
\hline $45-64$ yrs & $1.88(0.71-5.01)$ & 0.205 & $1.45(0.67-3.13)$ & 0.340 & $1.79(0.90-3.54)$ & 0.096 & $2.24(0.77-6.50)$ & 0.139 & $2.08(0.18-24.15)$ & 0.557 & $\dagger$ & $\dagger$ \\
\hline$\geq 65 \mathrm{yrs}$ & $2.39(0.88-6.50)$ & 0.089 & $0.84(0.35-2.01)$ & 0.689 & $2.30(1.13-4.68)$ & 0.021 & $4.09(1.43-11.67)$ & 0.009 & $10.20(1.16-89.48)$ & 0.036 & $\dagger$ & $\dagger$ \\
\hline \multicolumn{13}{|c|}{ Smoking status } \\
\hline Never & 1 & & * & & * & & * & & * & & $*$ & \\
\hline Former & $2.39(0.95-6.02)$ & 0.064 & * & * & $*$ & $*$ & * & $*$ & $*$ & $*$ & $*$ & $*$ \\
\hline Current & $1.48(0.43-5.05)$ & 0.531 & $*$ & $*$ & * & $*$ & * & $*$ & $*$ & $*$ & $*$ & $*$ \\
\hline \multicolumn{13}{|l|}{$\begin{array}{l}\text { Dust at } \\
\text { workplace }\end{array}$} \\
\hline Never & 1 & & 1 & & 1 & & 1 & & 1 & & 1 & \\
\hline $\begin{array}{l}\text { One year } \\
\text { or more }\end{array}$ & $1.49(0.92-2.43)$ & 0.107 & $1.54(0.98-2.41)$ & 0.059 & $1.46(0.98-2.17)$ & 0.060 & $2.76(1.67-4.56)$ & $<0.001$ & $1.61(0.50-5.20)$ & 0.426 & $2.67(1.15-6.20)$ & 0.023 \\
\hline
\end{tabular}

Cooking/heating

Using an

open fire

$\begin{array}{ll}\text { No } & 1 \\ \text { Yes } & 0.38(0.23-0.62)<0.001\end{array}$

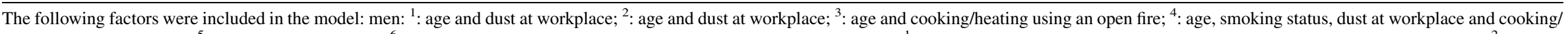

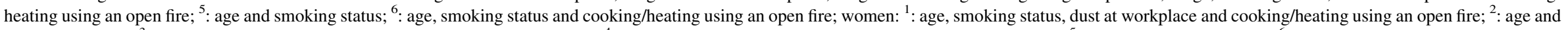

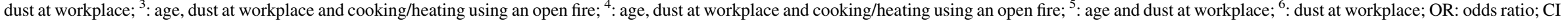
95\%: 95\% confidence interval; yrs: years; *: corresponding factor not selected for the multivariable analysis (univariate $P$-value $>0.20$ ); factor excluded from the analysis as there were not enough data. 
Table 4

Attributable risks percent for chronic respiratory diseases (AR\%, CI 95\%) for the overall sample and stratified by sex.

\begin{tabular}{|c|c|c|c|c|c|}
\hline & Rhinoconjuntivitis $^{1}$ & Asthma $^{2}$ & Chronic bronchitis $^{3}$ & Emphysema $^{4}$ & Tuberculosis $^{5}$ \\
\hline Variable & $\mathrm{AR} \%(95 \% \mathrm{CI})$ & $\operatorname{AR} \%(95 \% \mathrm{CI})$ & $\operatorname{AR} \%(95 \% \mathrm{CI})$ & $\mathrm{AR} \%(95 \% \mathrm{CI})$ & $\mathrm{AR} \%(95 \% \mathrm{CI})$ \\
\hline \multicolumn{6}{|l|}{ Overall } \\
\hline \multicolumn{6}{|l|}{ Smoking status } \\
\hline Former & $*$ & $*$ & $19.1(-44.5$ to 54.7$)$ & $63.6(-7.3$ to 87.6$)$ & $27.5(-54.0$ to 65.9$)$ \\
\hline Current & $*$ & $*$ & $36.3(-9.5$ to 62.9$)$ & $69.4(0.3$ to 90.6$)$ & 50.9 (6.5 to 74.2$)$ \\
\hline \multicolumn{6}{|l|}{ Dust at workplace } \\
\hline One year or more & 31.9 (16.3 to 44.6$)$ & $17.7(-11.2$ to 39.1$)$ & $51.8(31.2$ to 66.3$)$ & $34.6(-49.4$ to 71.4$)$ & $10.3(-45.1$ to 44.6$)$ \\
\hline \multicolumn{6}{|l|}{ Cooking/heating } \\
\hline \multicolumn{6}{|l|}{ Using an open fire } \\
\hline Yes & $12.6(-6.5$ to 28.4$)$ & $35.2(12.6$ to 52.0$)$ & $47.2(24.2$ to 63.3$)$ & $*$ & $*$ \\
\hline \multicolumn{6}{|l|}{ Men } \\
\hline \multicolumn{6}{|l|}{ Smoking status } \\
\hline Former & $*$ & $*$ & $44.2(-9.4$ to 71.6$)$ & $86.8(29.1$ to 97.6$)$ & $8.3(-129.0$ to 63.3$)$ \\
\hline Current & $*$ & $*$ & $48.6(3.5$ to 72.6$)$ & $88.2(39.7$ to 97.7$)$ & $45.6(-11.4$ to 73.4$)$ \\
\hline \multicolumn{6}{|l|}{ Dust at workplace } \\
\hline One year or more & $30.7(6.3$ to 48.8$)$ & $*$ & $35.0(-9.6$ to 61.5$)$ & $*$ & $*$ \\
\hline \multicolumn{6}{|l|}{ Cooking/heating } \\
\hline \multicolumn{6}{|l|}{ Using an open fire } \\
\hline Yes & $*$ & $38.8(-0.7$ to 62.8$)$ & $62.2(37.6$ to 77.0$)$ & $*$ & $43.7(-4.0$ to 69.6$)$ \\
\hline \multicolumn{6}{|l|}{ Women } \\
\hline \multicolumn{6}{|l|}{ Smoking status } \\
\hline Former & $*$ & $*$ & $*$ & $*$ & $*$ \\
\hline Current & $*$ & $*$ & $*$ & $*$ & $*$ \\
\hline \multicolumn{6}{|l|}{ Dust at workplace } \\
\hline One year or more & $13.0(-0.2$ to 24.4$)$ & $29.5(-1.5$ to 51.0$)$ & $61.9(38.5$ to 76.3$)$ & $37.3(-98.3$ to 80.2$)$ & $62.0(12.6$ to 83.5$)$ \\
\hline \multicolumn{6}{|l|}{ Cooking/heating } \\
\hline \multicolumn{6}{|l|}{ Using an open fire } \\
\hline Yes & $*$ & $32.6(2.1$ to 53.6$)$ & $21.8(-26.0$ to 51.5$)$ & $*$ & $*$ \\
\hline
\end{tabular}

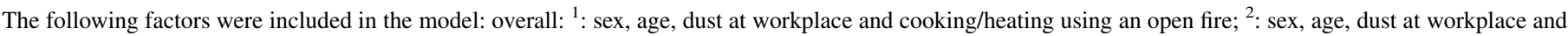

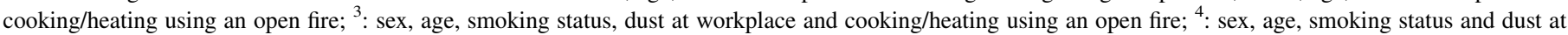

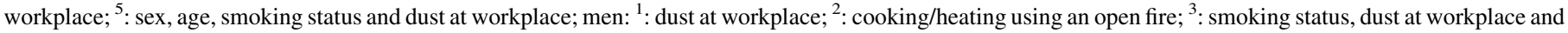

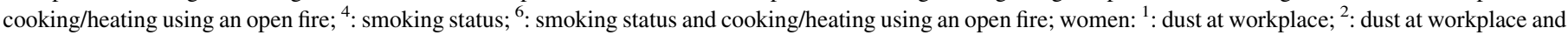

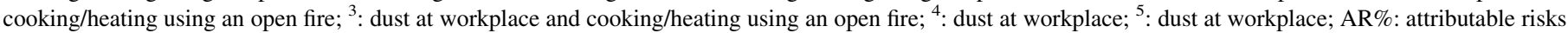
percent; CI 95\%: 95\% confidence interval; *: corresponding factor not selected for multivariable analysis (univariate $P$-value $>0.20$ ).

\section{Discussion}

Tobacco smoking, past exposure to dust at work, and cooking using an open fire are important risk factors for CRD in Cape Verde.

As estimated using appropriate epidemiological methods, the prevalence of COPD across the world ranged from $4 \%$ to up to $20 \%$ in adults $[18,19]$. We found an overall prevalence of $4.5 \%$ for chronic bronchitis and $0.7 \%$ for emphysema diagnosis. However, under-diagnosis and under-reporting of respiratory diseases exist in Cape Verde, as previously published [12].

The low prevalence of current smoking (5.2\%) could result from the definition used and to the fact that other forms of tobacco are popular in Cape Verde (i.e. chewing tobacco and snuff). Nevertheless, despite the low smoking prevalence in Cape Verde we found a high exposure to biomass burning and working in a dusty environment, both exhibiting important associations with the diseases studied.

Smoking is a major risk factor for COPD and seems also an important risk factor for tuberculosis infection documented by other authors [7]. The present paper points out the role of smoking on CRD, namely in men. It confirms the importance of other risk factors such as working in a dusty environment and cooking using an open fire. These exposures are common in many other African countries and should be taken in consideration when evaluating respiratory diseases in the Sub-Saharan region. The attributable risk percentages suggest that a considerable reduction in CRD could undoubtedly be achieved in Cape Verde if actions were taken to reduce these risk factors to an ideal exposure scenario (e.g. no exposure).

In our study, older individuals presented a higher risk of chronic bronchitis, emphysema and asthma, in accordance with the literature [20,21], though it is important to make the distinction between asthma and COPD, even in older patients, since optimal management must be based on different approaches [22].

The prevalence of asthma in children assessed in Cape Verde in 2002 was around 10\% [23]. In Mozambique, another African Portuguese-speaking country, the prevalence of current asthma and rhinoconjuctivitis in children was $13.3 \%$ and $23 \%$ [24].

The fact that biomass burning appeared as a protective factor for rhinitis diagnosis could be related with underdiagnosis of this disease, more pronounced in rural areas, and suggest a need for more accurate tools for rhinitis assessment [25].

There are few studies about the impact of asthma and COPD in Sub-Saharan countries, particularly in adults as pointed out 
by von Gemert et al. [3] in a clinical review. Tobacco smoking has traditionally been considered the main factor responsible for the development of COPD [8], not only in high- but also in middle-income countries. Moreover, the risk of developing CRD attributable to biomass smoke exposure is considered similar to the risk due to tobacco smoking [26]. Our results for the overall sample are in accordance with previous findings, even though biomass exposure seems to have a higher impact on men than suggested by other authors [27].

Increasing evidence indicates that gender diversity in respiratory health could be due to differences in pathophysiologic characteristics (smaller lung volumes in women, hormonal differences, comorbidity) [28], and environmental exposure. Biomass fuel burning exposure is identified as an important risk factor for CRD in both sexes, especially in women who are more exposed to cooking in unvented places [27]. Exposure to dust in the workplace is also considered a relevant exposure for both sexes and could be more significant for women because of their greater vulnerability [29]. Some studies have reported higher susceptibility in females to the deleterious effects of cigarette smoke [30]. Gender differences may occur as men and women seem to have a different ability to maintain redox status [31]. Moreover it was also proposed that racial differences exist regarding oxidative stress and inflammation [32].

We should note that as our sample was recruited at the primary healthcare level, it was not intended to be representative of the real Cape Verde population. In this regard, the median age of our sample was 30 years and $66 \%$ were women.

We may have not estimated the real prevalence of CRD at PHC facilities in Cape Verde as the length of the survey can be considered too short. Furthermore, as the excluded subjects from the data analysis presented significantly less prevalent $\mathrm{CRD}$, we may have overestimated the real prevalence.

Another limitation could result from seasonality although we chose the dry season as we considered it would be the best time of the year for seeking care at PHC departments. Conversely, despite the cultural adaptation, this was the first time that the questionnaire was used in such a large sample in Cape Verde.

However, our study presents several strengths. First of all, it applied the STROBE reporting guidelines. To our knowledge, this is the first African study having done so. Secondly, this study was part of the GARD initiative which will allow in the long-term comparisons among studies from different parts of the world.

As a consequence of these limitations, we cannot be sure about the extent to which the results of our study can be generalized. Nevertheless, we believe our findings may apply to people from Sub-Saharan Africa as they are consistent, plausible and coherent.

\section{Conclusion}

Tobacco smoking, past exposure to dust at work, and cooking using an open fire seem to be important risk factors for CRD in Cape Verde. Our results suggest that if actions were taken in order to reduce the aforementioned exposures, an important decrease in CRD prevalence would be achieved.

\section{Disclosure of interest}

Jean Bousquet has received honoraria for participation in scientific and advisory boards (Actelion, Almirall, Meda, Merck, MSD, Novartis, Sanofi-Aventis, Takeda, Teva, Uriach), lectures during meetings (Almirall, AstraZeneca, Chiesi, GSK, Meda, Merck, MSD, Novartis, OM Pharma, Sanofi-Aventis, Schering Plough, Takeda, Teva, Uriach) and Board of Directors (Stallergenes).

P. Carreiro-Martins, J. Rosado-Pinto, M. do Céu Teixeira, N. Neuparth, O. Silva, A.L. Papoila, N. Khaltaev, I. AnnesiMaesano declare that they have no conflicts of interest concerning this article.

\section{Acknowledgements}

This study was performed with the collaboration of the Health Ministries of Portugal (Direccão Geral de Saúde) and Cape Verde within the framework of Chronic Respiratory Diseases. The authors acknowledge all the healthcare professionals participating with the database, namely Dr. Helder Tavares (Medicine Department, Agostinho Neto Hospital, Praia), Dr. José Luís Spencer and Dr. Dulce Mascarenhas (Medicine Department, Dr. Baptista de Sousa Hospital, Mindelo) and Dr. Nila Godinho (Instituto Nacional de Estatística de Cabo Verde).

\section{References}

[1] Pauwels RA, Rabe KF. Burden and clinical features of chronic obstructive pulmonary disease (COPD). Lancet 2004;364(9434):613-20.

[2] http://www.who.int/gard/publications/GARD_actionplan_FINAL.pdf, Global Alliance Against Chronic Respiratory Diseases Action Plan 20082013. Date last accessed: January 2013.

[3] van Gemert F, van der Molen T, Jones R, Chavannes N. The impact of asthma and COPD in sub-Saharan Africa. Prim Care Respir J 2011; 20(3):240-8.

[4] Pauwels R. COPD: the scope of the problem in Europe. Chest 2000;117(5) [332S-5S, suppl 2].

[5] Janson C. The effect of passive smoking on respiratory health in children and adults. Int J Tuberc Lung Dis 2004;8(5):510-6.

[6] American Thoracic Society. What constitutes an adverse health effect of air pollution? Official statement of the American Thoracic Society. Am J Respir Crit Care Med 2000;161(2):665-73 [Pt 1].

[7] den Boon S, van Lill SW, Borgdorff MW, Verver S, Bateman ED, Lombard CJ, et al. Association between smoking and tuberculosis infection: a population survey in a high tuberculosis incidence area. Thorax 2005;60(7):555-7.

[8] Bousquet J, Khaltaev N. Global surveillance, prevention and control of chronic respiratory diseases: a comprehensive approach; 2007 [Date last accessed: January 2014, http://www.who.int/gard/publications/ GARD\%20Book\%202007.pdf].

[9] Ehrlich RI, White N, Norman R, Laubscher R, Steyn K, Lombard C, et al. Wheeze, asthma diagnosis and medication use: a national adult survey in a developing country. Thorax 2005;60(11):895-901.

[10] Ait-Khaled N, Odhiambo J, Pearce N, Adjoh KS, Maesano IA, Benhabyles B, et al. Prevalence of symptoms of asthma, rhinitis and eczema in 13- to 14-year-old children in Africa: the International Study of Asthma and Allergies in Childhood Phase III. Allergy 2007;62(3):247-58. 
[11] WHO meeting on the Global Alliance Against Chronic Respiratory Diseases (GARD); 2005 [Geneva, www.who.int/respiratory/publications/WHO NMH CHP CPM CRA 05.1pdf, date last accessed: January 2013].

[12] Martins P, Rosado-Pinto J, do Ceu Teixeira M, Neuparth N, Silva O, Tavares H, et al. Under-report and underdiagnosis of chronic respiratory diseases in an African country. Allergy 2009;64(7):1061-7.

[13] von Elm E, Altman DG, Egger M, Pocock SJ, Gotzsche PC, Vandenbroucke JP. The Strengthening the Reporting of Observational Studies in Epidemiology (STROBE) statement: guidelines for reporting observational studies. Lancet 2007;370(9596):1453-7.

[14] Buist AS, Vollmer WM, Sullivan SD, Weiss KB, Lee TA, Menezes AM, et al. The Burden of Obstructive Lung Disease Initiative (BOLD): rationale and design. Copd 2005;2(2):277-83.

[15] Hosmer DW, Lemeshow S, Sturdivant RX. Applied logistic regression. 3rd ed. New York: Wiley; 2013.

[16] Greenland S, Drescher K. Maximum likelihood estimation of the attributable fraction from logistic models. Biometrics 1993;49(3):865-72.

[17] Altman DG. Practical statistical for medical research. London: Chapman \& Hall; 1990.

[18] Viegi G, Pedreschi M, Pistelli F, Di Pede F, Baldacci S, Carrozzi L, et al. Prevalence of airways obstruction in a general population: European Respiratory Society vs American Thoracic Society definition. Chest 2000;117(5):339S-45S [Suppl 2].

[19] Halbert RJ, Isonaka S, George D, Iqbal A. Interpreting COPD prevalence estimates: what is the true burden of disease? Chest 2003;123(5):1684-92.

[20] Viegi G, Matteelli G, Angino A, Scognamiglio A, Baldacci S, Soriano JB, et al. The proportional Venn diagram of obstructive lung disease in the Italian general population. Chest 2004;126(4):1093-101.

[21] Soriano JB, Davis KJ, Coleman B, Visick G, Mannino D, Pride NB. The proportional Venn diagram of obstructive lung disease: two approximations from the United States and the United Kingdom. Chest 2003;124(2):474-81.

[22] Celli BR, MacNee W. Standards for the diagnosis and treatment of patients with COPD: a summary of the ATS/ERS position paper. Eur Respir J 2004;23(6):932-46.

[23] Rosado-Pinto J, Morais-Almeida M. Asthma in developing worlds. Pediatr Pulmonol Suppl 2004;26:66-8.

[24] Mavale-Manuel S, Joaquim O, Macome C, Almeida L, Nunes E, Daniel A, et al. Asthma and allergies in schoolchildren of Maputo. Allergy 2007; 62(3):265-71.

[25] Piau JP, Massot C, Moreau D, Ait-Khaled N, Bouayad Z, Mohammad Y, et al. Assessing allergic rhinitis in developing countries. Int J Tuberc Lung Dis 2010;14(4):506-12.

[26] Salvi S, Barnes PJ. Is exposure to biomass smoke the biggest risk factor for COPD globally? Chest 2010;138(1):3-6.

[27] Hu G, Zhou Y, Tian J, Yao W, Li J, Li B, et al. Risk of COPD from exposure to biomass smoke: a metaanalysis. Chest 2010;138(1):20-31.

[28] Chapman KR. Chronic obstructive pulmonary disease: are women more susceptible than men? Clin Chest Med 2004;25(2):331-41.

[29] Matheson MC, Benke G, Raven J, Sim MR, Kromhout H, Vermeulen R, et al. Biological dust exposure in the workplace is a risk factor for chronic obstructive pulmonary disease. Thorax 2005;60(8):645-51.

[30] Sorheim IC, Johannessen A, Gulsvik A, Bakke PS, Silverman EK, DeMeo DL. Gender differences in COPD: are women more susceptible to smoking effects than men? Thorax 2010;65(6):480-5.

[31] Malorni W, Campesi I, Straface E, Vella S, Franconi F. Redox features of the cell: a gender perspective. Antioxid Redox Signal 2007;9(11):1779801.

[32] Feairheller DL, Park JY, Sturgeon KM, Williamson ST, Diaz KM, Veerabhadrappa P, et al. Racial differences in oxidative stress and inflammation: in vitro and in vivo. Clin Transl Sci 2011;4(1):32-7. 